\title{
Poesia modernista. Gestos de ar e de pedra
}

\author{
Susana Scramim*
}

\section{Resumo:}

Propõe-se uma discussão sobre que tipo de análise podemos empreender com o Guia de Ouro Preto (1938) e com o poema "Ouro Preto" (1940), ambos de Manuel Bandeira. A relação com o visual tanto do guia quanto do poema está marcada por um ponto de vista modernista frente à cidade colonial. As imagens ali figuradas não estão pensadas numa relação de ausência-presença, mas sim na possibilidade de fixarem-se como pedra monumental, como memória. A análise aqui empenhada propõe-se a interrogar sobre a respiração do tempo nas imagens das obras e também se propõe a descobrir as afinidades paradoxais entre o ar e a pedra, isto é, entre a atmosfera e a matéria daquela arte dita colonial, afinidades essas que reencenam as relações entre a dança e a sepultura do modernismo com a arte colonial, portanto, barroca.

\section{Palavras-chave:}

Modernismo; neo-colonial; anacronismo; poesia

\section{4.}

Ano da viagem de Mário e Oswald de Andrade às cidades históricas de Minas Gerais durante a semana santa, na companhia de Blaise Cendrars, Tarsila do Amaral, Paulo Prado, Goffredo da Silva Telles e René Thiollier. Um mês antes, no dia 18 de março, Oswald de Andrade lançara o "Manifesto da Poesia Pau-Brasil" no suplemento "Letras e Artes" do jornal Correio da Manhã. Pouco depois, em outubro do mesmo ano, começa a publicar na Revista do Brasil poemas que irão compor no ano seguinte o livro Pau Brasil. Um desses poemas é "Documental", que mais tarde irá compor a seção "Roteiro de Minas", do livro Pau Brasil.

\footnotetext{
* Professora de Literatura da UFSC e pesquisadora do CNPq.
} 


\section{documental}

É o Oeste no sentido cinematográfico

Um pássaro caçoa do trem

Maior do que ele

A estação próxima chama-se Bom Sucesso

Floresta colinas cortes

E súbito a fazenda nos coqueiros

Um grupo de meninas entra no film

Figura no 1

Em castelhano o termo "documental" tem o sentido também de filme informativo. Fica então a pergunta: por que Oswald de Andrade teria preferido a grafia em castelhano do termo para escrever os poemas da viagem afetiva às cidades históricas de Minas Gerais? Podemos cogitar que, com "Documental" temos diante de nós a conjunção do valor do documento, da realidade, do fato, com o valor do documentário tomado como "maneira" de se registrar o fato, como "versão possível" para o documento. Dessa forma, o título nos traz de volta à primeira frase do "Manifesto da Poesia Pau Brasil": "A poesia existe nos fatos. Os casebres de açafrão e de ocre nos verdes da Favela, sob o azul cabralino, são fatos estéticos. [...] Alegria dos que não sabem e descobrem." (ANDRADE apud SCHWARTZ, 1995, p.136). O poema "Documental" quando inserido na coletânea Pau Brasil virá acompanhado de uma gravura de Tarsila do Amaral: 


\section{ROTEIRO DAS MINAS}

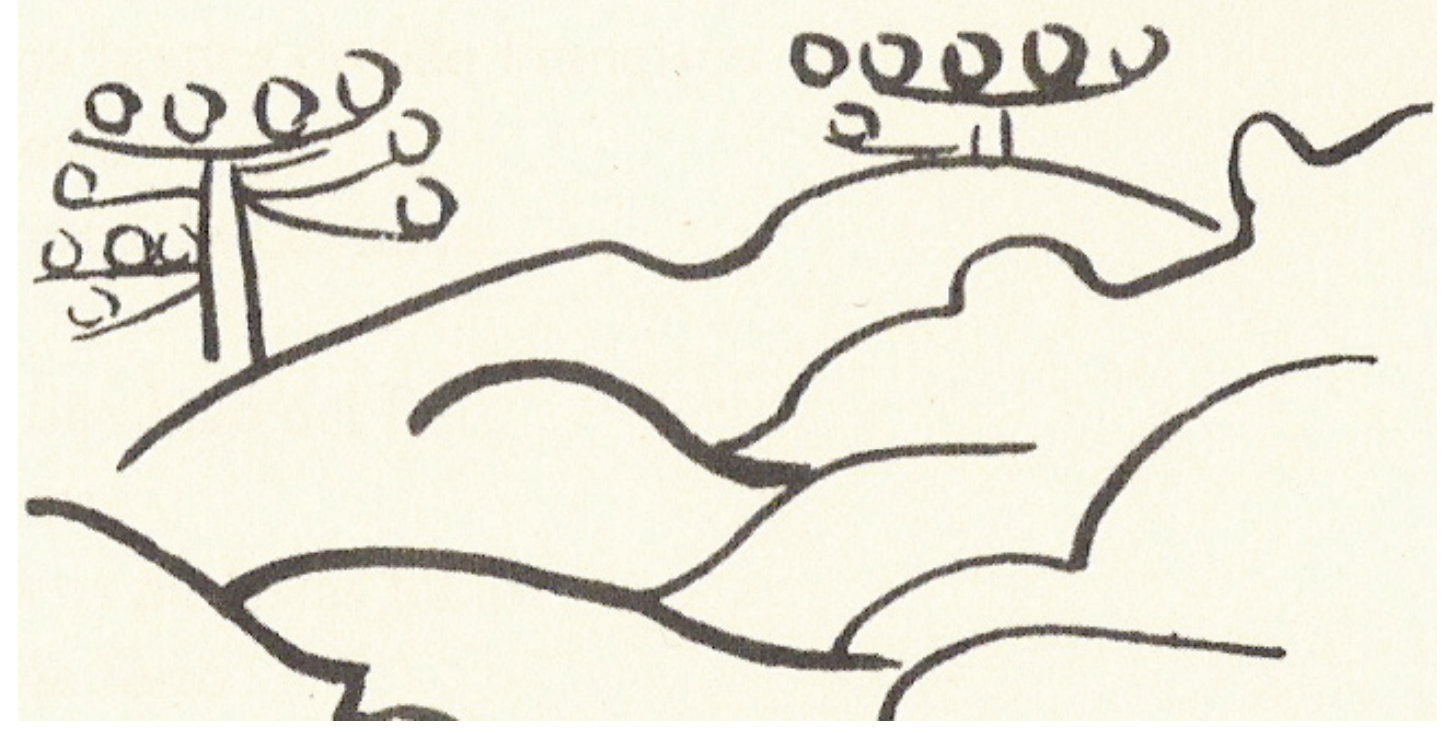

Figura no 2

"Documental" é procedimento de corte e de montagem da imagem e da imaginação, é documentário, pois que oferece informes sobre o processo de vir a ser e extinguir-se da sociedade colonial brasileira. Materializa-se com sua inserção numa concepção cíclica do tempo, portanto, numa temporalidade barroca em que a história natural é compreendida como pré e pós-história do homem. Dessa maneira, o poema é um documento do fato. Cada verso desse documento anacrônico da colônia que, entretanto, funciona sincronicamente como um documentário do que o poema vê em seu próprio tempo, é atravessado, nesse sentido, pelo realismo. Contudo, o poema é também um procedimento de montagem, e seus versos funcionam como uma tira de um rolo de filme cujos quadros foram recortados e montados, talvez numa tentativa de afastamento do realismo que o próprio gênero do documentário prevê e do gênero naturalista quando da pintura de paisagens. A linguagem resulta sintética, densa, só podendo ser pensada se imaginada.

Mas houve um estouro nos aprendimentos. Os homens que sabiam tudo se deformaram como borrachas sopradas. Rebentaram.

A volta à especialização. Filósofo fazendo filosofia, críticos, crítica, donas-de-casa tratando de cozinha. A Poesia para os poetas. Alegria dos que não sabem e descobrem. (Idem) 


\section{8.}

Mário de Andrade escreve seu primeiro texto sobre o Aleijadinho. ${ }^{1}$ No texto de 1928, Mário de Andrade compara e dá ênfase ao "mal estar" cultural que tanto paira sobre aqueles anos de modernismo vanguardista quanto no Brasil colonial. O argumento do qual Mário de Andrade se vale para a comparação entre a arte colonial e a modernista é o princípio teórico da deformação. Sobre a obra de Antônio Francisco Lisboa, o Aleijadinho, diz:

Raro realista, foi um deformador sistemático. Mas a sua deformação é duma riqueza, duma liberdade de invenção absolutamente extraordinárias. Falaram que ele ignorava escultura, e principalmente ignorava anatomia... Isto, aliás, não tinha importância nenhuma, porque confundir escultura com anatomia é que é ignorância vasta. (ANDRADE, 1984, p. 40)

\section{8.}

Manuel Bandeira produz o Guia de Ouro Preto. Este "Guia" de viagem é fruto de um trabalho de pesquisa ao qual o poeta Manuel Bandeira vinha dedicando-se já antes do primeiro ensaio de Mário de Andrade sobre Antônio Francisco Lisboa, isto é, 1928. Assim que, mesmo sem ter propriamente feito parte da caravana modernista que visitou Minas Gerais em 1924, Manuel Bandeira demonstra a sua adesão aos problemas e questões que o Modernismo vanguardista se propunha a investigar. $O$ interesse pela cultura colonial é um desses problemas.

Manuel Bandeira revelara a Mário de Andrade, mediante sua pesquisa sobre as cidades coloniais, o descaso que o artista Aleijadinho recebia de viajantes, historiadores e companheiros de outras artes. Mário de Andrade no ensaio de 1928 lembra que:

[...] o Aleijadinho está sem uma exegese completa. E os estrangeiros que nos visitaram, no geral se esqueceram dele, o que inda mais assusta a nossa timidez. Manuel Bandeira já se queixou disso, quando lembrou que foi Saint-Hilaire, o primeiro estranho "a se referir, em letra impressa, ao Aleijadinho". (Idem, p. 24)

É interessante pensar que Bandeira compõe o livro sobre Ouro Preto e sobre o mundo colonial, sob a forma de "Guia". Um guia serve para que, entre outras coisas, não nos equivoquemos, não erremos em relação ao caminho certo. Um guia, de fato, para que os viajantes modernistas não incorressem no mesmo erro

\footnotetext{
${ }^{1}$ Mário de Andrade publicará em 1935 esse mesmo ensaio sob o título "O Aleijadinho e sua posição nacional", no livro O Aleijadinho e Álvares de Azevedo. Rio de Janeiro, R.A. Editora. Em 1930, publica no Diário Nacional, na secção "Táxi", a crônica intitulada "Aleijadinho", na qual se refere a algumas questões já tratadas no ensaio de 1928, como por exemplo, a referência por parte dos viajantes estrangeiros no Brasil, não ao artista Antônio Francisco Lisboa, mas somente às suas obras. Refere-se também ao completo descaso que os escritores e historiadores árcades oferecem ao artista de tantas e tão visíveis obras.
} 
anacrônico dos viajantes e artistas coloniais. É como se ecoasse a mensagem: não nos esqueçamos de Aleijadinho!

O poema que serve de epígrafe ao Guia de Ouro Preto leva título de "Ouro Preto". Manuel Bandeira se refere ao poema em carta a Mário de Andrade como um poema parnasiano. Em carta datada de 5 de abril de 1928, Manuel Bandeira exorta ao amigo Mário de Andrade:

E ponha a fora o Macunaíma enquanto os bestalhões que andam fazendo brasilidades não acabam de desgastar a gente do Brasil, do modernismo, da literatura, de tudo! É preciso fechar o ciclo, urgentemente, com obra do pesado. Eu ando tão aporrinhado que fiz um soneto sobre Ouro Preto, sim senhor! Soneto alexandrino, com enjambements e chave de ouro do Tripuí! (ANDRADE e BANDEIRA, 2000, p.384)

E em 23 de agosto de 1928, refere-se à publicação do ensaio sobre o Aleijadinho e a do poema "Ouro Preto":

Agora o Álvaro Moreyra reúne às quintas uns amigos para jantar. Sou do cordão como colaborador das revistas. (No número de junho da Ilustração saiu o meu soneto parnasiano sobre Ouro Preto; no próximo sai o artigo sobre o Aleijadinho). (Idem, p. 399)

O poema, mesmo sendo um poema "parnasiano", mediante a linguagem figurada da qual se vale, permite ao leitor obliterar o aspecto tão fortemente pedagógico do guia.

\section{0.}

Manuel Bandeira publica no livro Lira dos Cinquënt'anos o poema "Ouro Preto" que em 1938 já servia de epígrafe ao Guia de Ouro Preto. 
Ouro branco! Ouro preto! Ouro podre! De cada Ribeirão trepidante e de cada recosto De montanha o metal rolou na cascalhada Para o fausto del-Rei, para a glória do imposto.

Que resta do esplendor de outrora? Quase nada: Pedras... templos que são fantasmas ao sol-posto. Esta agência postal era a Casa de Entrada... Este escombro foi um solar... Cinza e desgosto!

O bandeirante decaiu - é funcionário. Último sabedor da crônica estupenda, Chico Diogo escarnece o último visionário.

$\mathrm{E}$ avulta apenas, quando a noite de mansinho Vem, na pedra-sabão, lavrada como renda, - Sombra descomunal, a mão do Aleijadinho!

Figura no 3

O poema fora moldado, conformado, numa forma poética dura como a pedra, o soneto, mas não sem o movimento que a pedra adquire quando "lavrada". Portanto, nessa forma pura e clássica do soneto há uma deformação ao nível do sentido. O que outrora era riqueza, brilho e valor de troca, hoje se decompõe, "Ouro branco! Ouro preto! Ouro podre". O passado de luz sobrevive, contudo, como ruína, como vestígio. "E avulta, apenas, .... a sombra descomunal, a mão do Aleijadinho!". Há uma ativação da imagem pelo agir sensório-afetivo-motor. É noite, é sombra, é o "lavrar como renda" a pedra. Com essa ativação da imagem do vestígio, lembremos de que um vestígio não tem forma definida, um vestígio é uma deformação de uma forma anterior, com essa ativação da imagem ampliam-se os sentidos da imagem mesma, conduzindo o verbo pela moldagem das mãos, a mão descomunal do Aleijadinho, mãos deformadas se lembrarmos que ele amarrava as ferramentas aos braços para esculpir. Forçoso é lembrar do trecho do Manifesto da Poesia Pau Brasil transcrito nas páginas anteriores deste estudo: "Mas houve um estouro nos aprendimentos. Os homens que sabiam tudo se deformaram como borrachas sopradas. Rebentaram." (ANDRADE apud SCHWARTZ, 1995, p.136).

O princípio da deformação é o que atravessa a política estética desses modernistas. A deformação ativa um movimento que necessariamente recorre à imaginação para produzir na linguagem a poesia. No processo de deformar e recriar as imagens mais convencionais surge a imagem alegórica que é muito mais forte que a imagem convencional ou realista. "A sombra descomunal da mão do Alei- 
jadinho" surge na pedra-sabão, entretanto, ela é a pedra lavrada como renda. Conjugam-se aqui o animado e inanimado, a matéria e o sopro, a anti-matéria que produz novamente a matéria mediante o trabalho com as mãos. Nesse poema, conjugam-se de modo distinto do Guia de Ouro Preto o peso (o peso da tradição, as informações históricas, o arquivo histórico, a premência do reconhecimento e conservação do patrimônio) e a suspensão flutuante na forma de um soneto que se degenera mas que, antiteticamente, sobrevive no sopro da pedra, na renda que a imaginação cria na pedra-sabão, pela "sombra descomunal da mão do Aleijadinho".

A relação com o visual tanto do Guia de Ouro Preto quanto do poema está marcada por um ponto de vista modernista frente à cidade colonial, este ponto de vista é organizado a partir de um princípio deformador, menos no Guia e mais no poema. As imagens figuradas no poema estão pensadas numa relação de ausênciapresença, e não na possibilidade de fixarem-se como pedra monumental, como memória, como presença percebida no caso das imagens-monumento do Guia de Ouro Preto. A ausência produz uma "teoria do sopro indistinta de uma teoria da imagem" que explora a relação entre os corpos e as palavras, entre o sopro e a imagem, conforme analisa Georges Didi-Huberman - na homenagem que presta ao pensamento de Pierre Fédida - em Gestes d'air et de Pierre (2005). Há afinidades paradoxais entre o ar e a pedra, entre a deformação soprada na borracha em Oswald de Andrade e a lavra na pedra-sabão de Manuel Bandeira, portanto, entre a atmosfera e a matéria daquela arte dita colonial e a autodenominda arte modernista, afinidades essas que reencenam as relações entre a dança e a sepultura do modernismo e a arte colonial e, dessa maneira, configurando relações barrocas.

\section{Índice das figuras:}

Figura no 1: Poema "Documental" de Oswald de Andrade em Pau Brasil. Obras Completas. São Paulo: Globo, 2003, p.184.

Figura no 2: Gravura de Tarsila do Amaral para o poema "Documental" em Pau Brasil, op. cit., p. 175.

Figura no 3: Poema "Ouro Preto" de Manuel Bandeira do livro Lira dos Cinquënt'anos em Estrela da vida inteira. Rio de Janeiro: José Olympio. 1976, p 140.

\section{Bibliografia:}

ANDRADE, Mário de e BANDEIRA, Manuel. Correspondência. Org. Marco Antonio de Moraes. São Paulo: Edusp, 2000.

ANDRADE, Mário de. Aspectos das Artes Plástica no Brasil. 3aed. Belo Horizonte: Ed. Itatiaia, 1984.

ANDRADE, Oswald de. "Manifesto da Poesia Pau-Brasil". In: SCHWARTZ, Jorge, Vanguardas Latino-Americanas. Polêmicas, manifestos e textos críticos. São Paulo: Edusp, 1995.

. Pau Brasil. Obras Completas. São Paulo: Globo. 2003. 
BANDEIRA, Manuel. Guia de Ouro Preto. 4a ed. São Paulo: Editora Tecnoprint, $\mathrm{s} / \mathrm{d}$.

. Estrela da vida inteira. Rio de Janeiro: José Olympio. 1976.

. Seleta de prosa. Org. Júlio Castañon Guimarães. Rio de Janeiro: Nova Fronteira, 1997.

DIDI-HUBERMAN, Georges. Gestes d'air et de pierre. Corps, parole, souffle, image. Paris: Editions du Minuit, 2005.

Title:

Modernist poetry. Gestures of air and of stone

\begin{abstract}
:
Here a discussion is proposed on what kind of analysis one can carry out with the Guia de Ouro Preto (1938) and with the poem "Ouro Preto" (1940), both by Manuel Bandeira. The relation with the visual, both in the guide and in the poem is marked by a modernist point of view in face of the colonial city. The images there pictured are not thought of in a relation absence-presence, but in the possibility of fixating them as cornerstones, as memory. The analysis here presented interrogates about the breath of time in the images of the works and also strives to discover the paradoxical affinities between air and stone, that is, between the atmosphere and the raw matter of that art known as colonial, affinities that reenact the relations between the dance and the tomb of Modernism with the colonial art, and thus, Baroque art.
\end{abstract}

\title{
Keywords:
}

Modernism; neo-colonial; anachronism; poetry 